\title{
Simulation Use in Entry-Into-Practice Respiratory Care Programs
}

\author{
Samantha P Davis, Camille F Stover, and Janet K Willhaus
}

\begin{abstract}
BACKGROUND: Teaching and learning using simulation-based methods is increasing in health professions education; however, the prevalence of simulation use in respiratory care programs to date has not been explored. METHODS: All 412 Commission on Accreditation for Respiratory Care (CoARC)-accredited entry-into-practice respiratory care programs were e-mailed a survey inquiring about simulation use as an educational tool in their programs. RESULTS: Of the initial 412 programs contacted, 124 returned the survey, for a 30\% response rate. More than three-quarters of programs reported using simulation including $87 \%$ of associate degree programs, $75 \%$ of bachelor's degree programs, and $100 \%$ of master's degree programs. Simulation modalities differed by course and program as did length of simulation activities and debriefings. Simulation hours may not be substituted for learner's clinical time under CoARC guidelines, and $69 \%$ of respondents agreed with this stance; however, $66 \%$ of responding programs have mandatory simulation learning activities, and $68 \%$ believe the amount of simulation should be increased. The survey also revealed respiratory care faculty have limited training in the use of simulation. CONCLUSIONS: Simulationbased teaching and learning is widespread and varied, but there is a lack of faculty development in its use among respiratory care programs. Key words: simulation; entry into practice; debriefing; respiratory care education; simulation in respiratory care; health care simulation; undergraduate; faculty development. [Respir Care 0;0(0):1-๑. (C) 0 Daedalus Enterprises]
\end{abstract}

\section{Introduction}

Simulation-based learning is an immersive instructional method used throughout the health professions to prepare trainees for clinical practice using targeted, real-time instruction and feedback. ${ }^{1}$ Simulation-based learning may improve knowledge, confidence, competence, and self-efficacy in prelicensure students. ${ }^{2}$ Simulated environments afford educators the ability to monitor learner's proficiency from novice to competent in a controlled and safe learning

Ms Davis is affiliated with Henry Ford Health System International, Detroit, Michigan. Ms Stover is affiliated with Department of Respiratory Care, Boise State University, Boise, Idaho. Dr Willhaus is affiliated with Fay W. Whitney School of Nursing, University of Wyoming, Laramie, Wyoming.

The authors have disclosed no conflicts of interest.

This study was supported by a faculty research grant from the Department of Respiratory Care, Boise State University.

Correspondence: Samantha Davis MSc RRT RRT-NPS, HFHS International, Henry Ford Health System, Detroit, MI. E-mail:

sdavis55@hfhs.org.

DOI: $10.4187 /$ respcare. 08673 environment. Accrediting bodies and educators alike are shifting toward competency-based assessment models that engage learners in hands-on training and allow them to receive formative feedback that can be immediately implemented. ${ }^{3}$ As health professions programs continue to grow throughout the nation, academic programs are challenged to secure clinical experiences for all students, and simulation may be a valuable supplement. ${ }^{2}$

The need for innovation and exploration of alternate clinical placements became strikingly clear during the COVID-19 pandemic when in-person training was canceled for many. Simulation-based learning is deemed a valid substitution for traditional clinical hours for some health profession disciplines, such as paramedicine and nursing. . $^{2,5}$ The Commission on Accreditation for Respiratory Care (CoARC) 2020 Entry Into Practice Standards encourage use of simulation-based learning when adjunctive to traditional clinical experiences but do not consider simulation to be a valid substitute for traditional clinical hours or competency assessment. ${ }^{6}$ Faculty and student experiences with different simulation methods are reported in health professions research, but information specific to entry-into-practice respiratory care programs is lacking. ${ }^{7}$ The purpose of this study was to determine simulation utilization and challenges in 


\section{Simulation in ResPiRatory CARE Programs}

CoARC-accredited entry-into-practice respiratory care programs across the United States.

\section{Methods}

In January 2019, a Qualtrics survey was e-mailed to the program director of each CoARC-accredited entry-into-practice respiratory care program $(N=412)$. E-mail contacts were retrieved from the CoARC web site where they are publicly available. After receiving approval from the executive leadership team of the American Association for Respiratory Care (AARC), the survey was also posted to the AARC's Education Section listserv. CoARC program numbers were requested to eliminate any duplicate responses. Only surveys with valid CoARC program numbers were considered. The responses were de-identified by a respiratory care faculty member not involved in the initial survey before they were tabulated by question. A total of 124 nonduplicated surveys were received, for a response rate of $30 \%$. This inquiry project received an exempt designation by the Boise State University Institutional Review Board. Respondents were eligible to receive a \$10 Amazon gift card after survey completion.

\section{Survey Instrument}

The 23-item survey was consolidated and adapted from an initial survey of nursing education program use of simulation prevalence and practices conducted by the National Council of State Boards of Nursing (NCSBN). ${ }^{4,8}$ The survey included multiple-choice, select-all-that-apply, and free-text responses that inquired about demographics, training, debriefing, simulation modality, accreditation, and recommendations for equivalent clinical time. Simulationbased learning activities may include a variety of methods such as, but not limited to, screen-based computer simulation, high-fidelity simulation with a manikin or standardized patient, and procedure simulations with task trainers. Examples of these methods could be branching logic modules for credentialing examination preparation, neonatal resuscitation training with a manikin that exhibits chest rise and breath sounds, or a head-chest manikin for tracheal intubation training, respectively. Definitions of high-fidelity simulation, computer-based simulation, and task trainer were adapted from the Healthcare Simulation Dictionary and embedded within the survey. ${ }^{9}$ See Table 1 for definitions.

\section{Results}

One-hundred and twenty-four programs responded to the survey, for a $30 \%$ response rate; more than three-quarters reported using simulation education. Of the programs that responded, $87 \%$ of associate degree programs (83), $75 \%$ of bachelor's degree programs (30), and 100\% of master's

\section{QUICK LOOK}

\section{Current knowledge}

The use of simulation-based teaching and learning is increasing in health professions education; however, accreditation standards vary widely among disciplines. The Commission on Accreditation for Respiratory Care does not allow simulation to substitute for traditional clinical hours. Simulation-based learning is encouraged as an adjunct to traditional clinical experiences.

\section{What this paper contributes to our knowledge}

Many accredited entry-into-practice respiratory care programs use simulation-based learning. Simulation modalities and length of time for scenarios and debriefing vary between, and sometimes within, programs. Although time spent in simulation cannot be substituted for clinical hours, many programs have mandatory simulation-based learning activities and believe that simulation use should increase. Training for faculty who conduct simulation is limited, and few respondents were aware of best-practice standards for simulation.

degree entry-into-practice programs (5) use simulation. Many respondents indicated they offer more than one kind of degree program. These demographics are consistent with the proportion of CoARC-accredited associate, bachelor's, and master's degree programs in the United States. See Table 2 for a demographic summary of responding programs, institution types, locations, and numbers of graduates annually.

Responding programs incorporated high-fidelity simulation activities involving manikins or standardized patients most commonly into foundations of adult therapeutics,

\section{Table 1. Simulation Definitions}

\begin{tabular}{cc}
\hline \hline $\begin{array}{c}\text { High-Fidelity } \\
\text { Simulation }\end{array}$ & $\begin{array}{c}\text { Patient care scenario that uses a standardized patient } \\
\text { or a full-body manikin that has the ability to } \\
\text { mimic, at a very high level, human body func- } \\
\text { tions. High-fidelity simulation experiences are } \\
\text { highly realistic and provide a high level of inter- } \\
\text { activity and realism for the learner. }\end{array}$ \\
& $\begin{array}{c}\text { The modeling of real-life processes with inputs and } \\
\text { outputs exclusively confined to a computer. } \\
\text { Simulation } \\
\text { Subsets of computer-based simulation include } \\
\text { virtual patients, virtual-reality task trainers, and } \\
\text { immersive virtual-reality simulation. }\end{array}$ \\
& $\begin{array}{c}\text { A device designed to train in just the key elements } \\
\text { Task Trainer the procedure or skill being learned (such as }\end{array}$ \\
& $\begin{array}{l}\text { insertion, injection) or just in part of a total } \\
\text { system. }\end{array}$ \\
\hline
\end{tabular}




\section{Simulation in ResPiRatory CARE Programs}

Table 2. Demographic Information

\begin{tabular}{lr}
\hline \hline & No. \\
\hline Type of Program & \\
Associate & 95 \\
Baccalaureate & 40 \\
Graduate & 17 \\
Other & 1 \\
Type of Institution & \\
Academic/teaching medical center & 11 \\
University/college & 24 \\
Community college/technical school & 77 \\
Geographic Setting & \\
Urban/metro area & 60 \\
Suburban & 38 \\
Rural & 24 \\
Programs by Graduate Numbers & \\
$\leq 10$ & 16 \\
$10-50$ & 99 \\
$51-100$ & 3 \\
$\geq 100$ & 1 \\
\hline
\end{tabular}

Table 3. Type and Amount of Simulation Use in Courses

\begin{tabular}{lccc}
\hline \hline \multicolumn{1}{c}{ Course } & High Fidelity & Computer & Task Trainer \\
& no. $(\%)$ & no. $(\%)$ & no. $(\%)$ \\
\hline Foundations of adult therapeutics & $58(47)$ & $45(36)$ & $72(58)$ \\
Neonatal/pediatrics & $59(48)$ & $41(33)$ & $6(5)$ \\
Adult critical care & $96(77)$ & $64(52)$ & $53(43)$ \\
Patient assessment & $90(73)$ & $54(44)$ & $65(52)$ \\
\hline
\end{tabular}

neonatal/pediatrics, adult critical care, and patient assessment courses. The number of programs offering these courses and corresponding simulation use is listed in Table 3.

In addition to simulation with manikins, $50 \%$ of respondents reported using live actors or standardized patients in their simulation programs. Approximately 30\% used advanced lung simulators, such as commercially available products from Gaumard, IngMar Medical, Laerdal, or Michigan Instruments. Internet virtual hospital programs $(21 \%)$ and computer screen-based simulations (22\%), such as those independently developed or commercially available from Body Interact, were also widely used. A small number of programs (2\%) reported using immersive or virtual reality simulation, such as those independently developed or commercially available from Oxford Medical Simulation.

The length of time allocated for a simulation scenario and debriefing differed among schools, and some programs reported length of scenarios varied within the program. Approximately $81 \%$ (100) of responding programs indicated that they used simulation scenarios lasting 15-30 min; however, some programs $(56 \%, 69)$ reported scenarios that lasted $31-60 \mathrm{~min}$, and others $(44 \%, 55)$ used scenarios that lasted more than an hour. Respondents selected more than one time allocation when their program offered more than one simulation scenario length. Debriefing duration also varied from no debriefing to debriefing sessions that lasted as long or longer than the actual simulation scenario (See Table 4). Only 33\% (41) of respondents reported using a structured debriefing method, whereas $60 \%$ (74) did not use a structured method, and 2\% (3) did not debrief at all. The 3 most reported structured debriefing methods used were Promoting Excellence and Reflective Learning in Simulation (PEARLS), ${ }^{10}$ advocacy/inquiry, ${ }^{11}$ and Plus/Delta. ${ }^{12}$

Most programs indicated limited faculty development training in simulation. Whereas $45 \%$ (55) reported faculty were trained on how to run a simulation scenario, only $40 \%$ (49) said faculty were trained in debriefing. Approximately one-third of programs reported faculty training in scenario development and manikin programming. Only 28\% (35) of respondents indicated familiarity with the International Nursing Association for Clinical Simulation and Learning (INACSL) Standards of Best Practice: Simulation. ${ }^{13}$ The standards were renamed the Healthcare Simulation Standards in 2021; however, the former name is used here as it was current at the time of the study. ${ }^{14}$ Even fewer $(15 \%, 18)$ reported working in a simulation program accredited by the Society for Simulation in Healthcare.

CoARC does not allow simulation hours to be substituted for learner's clinical time, and most respondents $(69 \%, 85)$ agreed with that stance. Despite these findings, $66 \%$ (82) of responding programs have mandatory simulation learning activities, and 68\% (84) believe that the amount of simulation being used should increase.

\section{Discussion}

Compared to colleagues in nursing and medicine, the respiratory care profession lags behind in the adoption and utilization of simulation-based education. These findings are expected as the respiratory care profession is much newer in comparison, and the authors are encouraged by the current widespread use of simulation in entry-into-practice programs. Themes that emerged from this study that warrant further discussion are faculty development, debriefing, and standards of best practice.

Results of this survey indicate that faculty development in simulation for respiratory care educators is fragmented and sparse. Fewer than half of all respondents indicated receiving any faculty development in simulation design, debriefing, or technology-based instruction. Lack of faculty development may be related to limited financial resources, insufficient time or space, or a general scarcity of simulation research in respiratory care education demonstrating the need for such training. Without facilitators who are trained in simulation pedagogy and able to deliver consistent experiences that are formally evaluated, the outcomes 


\section{Simulation in Respiratory CARe Programs}

Table 4. Debriefing Time by Simulation Scenario Duration

\begin{tabular}{lrccc}
\hline \hline \multicolumn{2}{c}{$\begin{array}{c}\text { Simulation Scenario Duration } \\
\text { no. }(\%)\end{array}$} & $\begin{array}{c}\text { No Debriefing } \\
\text { no. }(\%)\end{array}$ & $\begin{array}{c}\text { Debriefing Time Less Than Scenario } \\
\text { no. }(\%)\end{array}$ & $\begin{array}{c}\text { Debriefing Time Equal to or Longer Than Scenario } \\
\text { no. }(\%)\end{array}$ \\
\hline $15-30 \mathrm{~min}$ & $100(81)$ & $3(3)$ & $47(38)$ & $50(40)$ \\
$31-60 \mathrm{~min}$ & $69(56)$ & $1(1)$ & $46(37)$ & $22(18)$ \\
$>60 \mathrm{~min}$ & $55(44)$ & $2(2)$ & $43(35)$ & $10(8)$ \\
\hline
\end{tabular}

of simulation-based learning are difficult to measure..$^{10}$ Variable learner experiences and the inability to articulate return on investment to administrators may create a snowball effect leading to lack of buy-in and inadequate resource allocation, making it even more difficult to launch or maintain a simulation program. Simulation is an instructional technique informed by learning theories, intended to enhance and supplement real experiences with guided experiences. ${ }^{15}$ To get distracted by the bells and whistles of cutting-edge technology without investing time and effort to learn simulation pedagogy is a common pitfall but is short-sighted and may have lasting negative effects.

Faculty development in simulation spans all phases of the process from design and facilitation to debriefing and operations. Through membership in professional societies, attendance at international conferences, and participation in stand-alone workshops, aspiring simulationists can gain the knowledge and skill needed to deliver high-quality simulation experiences. Debriefing is an important aspect of faculty development in simulation that has its own dedicated courses and standards of best practice. The simulation facilitator's role is to ensure an environment where lessons learned in the didactic and simulation environments can be translated and applied to clinical practice. In debriefing, learners will recount their experiences, celebrate successes, and debate shortcomings, but the facilitator is needed to guide the discussion from description to analysis to application. ${ }^{10}$

Whereas most survey respondents indicated that they engage in debriefing as part of their simulation practice, nearly two-thirds indicated that they do not use a structured approach. Among those who engage in structured debriefing, PEARLS,${ }^{10}$ advocacy/inquiry, ${ }^{11}$ and Plus/Delta ${ }^{12}$ were most used. PEARLS is a conceptual debriefing framework focused on learner's self-assessment, facilitating focused discussion, and providing information in the form of direct feedback. ${ }^{10}$ Advocacy/inquiry is a conversational tool embedded within the Debriefing with Good Judgment model that involves pairing one's stated perspective with an openended inquiry to learn more about others' perspectives. ${ }^{11}$ Plus/Delta is a debriefing technique where learner's actions are placed into columns labeled plus $(+)$ and delta $(\Delta)$, indicating which actions should be continued or changed, respectively. ${ }^{12}$ Structured debriefing methods exist beyond those described here and are largely selected by facilitator preference. ${ }^{15}$ Novice simulation educators may use scripted and structured debriefing to improve learner's knowledge acquisition while standardizing the debriefing process. ${ }^{16}$ Expert simulation educators often do not ascribe to any specific debriefing method but rather use the method most relevant to the learning objectives, scenario, location, and overall situation. ${ }^{17}$ With only $40 \%$ of survey respondents indicating that faculty receive professional development in simulation debriefing, it is not surprising that $60 \%$ do not use any structured debriefing method. Without training or mentorship, faculty may be unaware of structured debriefing methods, their proper use, or lack confidence in their debriefing facilitation skills. Professional development opportunities and funding are needed to better prepare respiratory care educators for simulation practice.

Respondents' unfamiliarity with INACSL Standards of Best Practice: Simulation offers an excellent opportunity to learn from our colleagues in other disciplines regarding best practices in simulation. Instead of starting from scratch, respiratory care educators and simulationists should seek guidance from those who have done this work for decades. Our colleagues have put energy into developing and vetting standards of best practice that can inform our simulation practice and its integration into our academic programs and accreditation standards. Other professional organizations, such as the Association of Standardized Patient Educators and The Gathering of Healthcare Simulation Technology Specialists, have created standards of best practice specific to standardized patients and simulation operations. ${ }^{18,19}$ Examples of these standards are outlined in Table 5. Beyond the knowledge gained through learning and integrating these standards into our practice, they provide a foundation for those interested in seeking simulation accreditation. Adapting the various standards of best practice may better prepare respiratory care educators to articulate return on investment, secure funding for equipment or professional development, engage in scholarship to advance the profession, or obtain simulation leadership roles.

\section{Limitations}

There are a few limitations to this study. First, the data represent a snapshot in time. Recent global changes in medicine, education, and simulation may have impacted the use of simulation in respiratory care programs. Second, the response 


\section{Simulation in Respiratory Care Programs}

Table 5. Examples of Best-Practice Standards in Simulation

\begin{tabular}{|c|c|c|}
\hline Standard & Author & Brief Description \\
\hline Simulation Design & $\begin{array}{l}\text { INACSL Standards of Best Practice: } \\
\text { Simulation }\end{array}$ & $\begin{array}{l}\text { Recommends criteria for achieving optimal simulation } \\
\text { design, such as performing a needs assessment, par- } \\
\text { ticipant evaluation, and debriefing }\end{array}$ \\
\hline Debriefing & $\begin{array}{l}\text { INACSL Standards of Best Practice: } \\
\text { Simulation }\end{array}$ & $\begin{array}{l}\text { Recommends criteria for achieving optimal debriefing, } \\
\text { such as facilitator competency and learning } \\
\text { environment }\end{array}$ \\
\hline Training Standardized Patients & $\begin{array}{l}\text { Association of Standardized Patient } \\
\text { Educators Standards of Best Practice }\end{array}$ & $\begin{array}{l}\text { Describes principles of SP training methodology, } \\
\text { including preparation for training, training for role } \\
\text { portrayal, training for feedback, training for comple- } \\
\text { tion of assessment instruments, and reflection on the } \\
\text { training process }\end{array}$ \\
\hline Professional Development & $\begin{array}{l}\text { Association of Standardized Patient } \\
\text { Educators Standards of Best Practice }\end{array}$ & $\begin{array}{l}\text { Describes principles of SP professional development, } \\
\text { including career development, scholarship, and } \\
\text { leadership }\end{array}$ \\
\hline Domains of Practice & $\begin{array}{l}\text { The Gathering of Healthcare Simulation } \\
\text { Technology Specialists }\end{array}$ & $\begin{array}{l}\text { Describes practice domains such as information tech- } \\
\text { nology, theatrics and staging, and management and } \\
\text { operations }\end{array}$ \\
\hline Core Competencies & $\begin{array}{l}\text { The Gathering of Healthcare Simulation } \\
\text { Technology Specialists }\end{array}$ & $\begin{array}{l}\text { Describes core competencies such as audiovisual tech- } \\
\text { nology, research and evaluation, and education }\end{array}$ \\
\hline
\end{tabular}

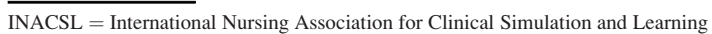

$\mathrm{SP}=$ standardized patient

rate of $30 \%$ is less than desired despite following best practices in electronic survey distribution. Recent literature suggests that low response rates may have little correlation to nonresponse bias; however, we recognize this limitation. ${ }^{20-21}$ Survey responses were representative of entry-into-practice undergraduate and graduate programs in rural and urban areas throughout the United States. In addition to e-mail distribution, the survey was shared via the AARC's Education Section listserv to capture more responses; however, this method only reaches those who are members of both the AARC and the Education Section. This study may underrepresent entry-into-practice respiratory care programs not using simulation because those program faculty may have declined to participate in the survey.

\section{Conclusions}

The use of simulation in entry-into-practice respiratory care programs is widespread, though highly varied. Challenges of the clinical environment include limited availability of high-quality clinical experiences, matching student learning objectives to the available patient population, and ensuring equitable training opportunities for all learners. Simulation-based learning is an instructional technique that can be used to address these challenges; however, it requires training, ongoing faculty development, and resources to be most effective. The desire for simulation-based learning in respiratory care is clear, but the lack of standardization may be our most significant hurdle to overcome. Future research should focus on faculty development in respiratory care simulation and the use of simulation in respiratory care education given the challenges of COVID-19.

\section{ACKNOWLEDGMENTS}

We would like to acknowledge Dr Joe Coyle and Lonny Ashworth for their assistance with survey development and data de-identification.

\section{REFERENCES}

1. Weller JM, Nestel D, Marshall SD, Brooks PM, Conn JJ. Simulation in clinical teaching and learning. Med J Aust 2012;196(9):594.

2. Cant RP, Cooper SJ. The value of simulation-based learning in prelicensure nurse education: a state-of-the-art review and meta-analysis. Nurse Educ Pract 2017;27:45-62.

3. Kalaniti K, Campbell DM. Simulation-based medical education: time for a pedagogical shift. Indian Pediatr 2015;52(1):41-45.

4. Hayden JK, Smiley RA, Alexander M, Kardong-Edgren S, Jeffries PR. The NCSBN national simulation study: a longitudinal randomized controlled study replacing clinical hours with simulation in prelicensure nursing education. J Nurs Regul 2014;5(2):S3-S40.

5. McKenna KD, Carhart E, Bercher D, Spain A, Todaro J, Freel J. Simulation use in paramedic education research (SUPER): a descriptive study. Prehosp Emerg Care 2015;19(3):432-440.

6. Commission on Accreditation in Respiratory Care. Accreditation standards for entry into respiratory care professional practice. July 1 , 2020. https://coarc.com/wp-content/uploads/2021/04/CoARC-EntryStandards-7.1.2020-clarif-3.21.pdf. Accessed October 10, 2021

7. Cuchna JW, Walker SE, Van Lunen BL. Simulations and standardized patients in athletic training: part 1 athletic training educators' use and perceptions. Athl Train Educ J 2019;14(1):35-47. 


\section{Simulation in Respiratory CaRe Programs}

8. Hayden J. Use of simulation in nursing education: national survey results. J Nurs Regul 2010;1(3):52-57.

9. Lioce L, Lopreiato J, Downing D, Chang TP, Robertson JM, Anderson M, Diaz DA, Spain AE, editors. Healthcare Simulation Dictionary-Second Edition. Rockville, MD: Agency for Healthcare Research and Quality; September 2020.

10. Bajaj K, Meguerdichian M, Thoma B, Huang S, Eppich W, Cheng A. The PEARLS health care debriefing tool. Acad Med 2018;93(2):336.

11. Rudolph JW, Simon R, Dufresne RL, Raemer DB. There's no such thing as "nonjudgmental" debriefing: a theory and method for debriefing with good judgment. Simul Healthe 2006;1(1):49-55.

12. Fanning RM, Gaba DM. The role of debriefing in simulation-based learning. Simul Healthc 2007;2(2):115-125.

13. INACSL standards of best practice: simulation design. Clin Simul Nurs 2016;12(Suppl):S5-S12.

14. INACSL Standards Committee, Healthcare Simulation Standards of Best Practice, Clin Simul Nurs, 2021; 58.

15. Gaba DM. The future vision of simulation in health care. BMJ Qual Saf 2004;13(suppl_1):i2-i10.
16. Cheng A, Hunt EA, Donoghue A, Nelson-McMillan K, Nishisaki A, LeFlore J, et al; EXPRESS Investigators. Examining pediatric resuscitation education using simulation and scripted debriefing: a multi-center randomized trial. JAMA Pediatr 2013;167(6):528-536.

17. Cheng A, Grant V, Dieckmann P, Arora S, Robinson T, Eppich W. Faculty development for simulation programs: five issues for the future of debriefing training. Simul Healthc 2015;10(4):217-222.

18. Steer K, Paschal B, Hillman T. Capability Framework for Healthcare Simulation Technology Specialists, 1st edition. Las Vegas: The Gathering of Healthcare Simulation Technology Specialists Inc; 2019.

19. Lewis KL, Bohnert CA, Gammon WL, Hölzer H, Lyman L, Smith C, et al. The Association of Standardized Patient Educators (ASPE) standards of best practice (SOBP). Adv Simul (Lond) 2017;2(1):10.

20. Assessing the representativeness of public opinion surveys. The Pew Research Center, Washington, District of Columbia: 2012.

21. Hendra R, Hill A. Rethinking response rates: new evidence of little relationship between survey response rates and nonresponse bias. Eval Rev 2019;43(5):307-330. 